\title{
Assessing the Role of Coping Styles as Mediators for Hope and Optimism in Measuring Academic Motivation among First Generation Learners
}

\author{
Dr. Ruchi Gautam*, Sachita Passi**
}

\begin{abstract}
The present study was conducted to examine the impact of positive psychological strengths hope and optimism on academic motivation. To study the role of proactive coping, avoidance coping and emotion coping as a mediator of hope and optimism with academic motivation of students. College students participated. Significant positive relations found for hope and optimism. Regression analysis showed proactive coping significantly mediated the relations of hope and optimism with academic motivation.
\end{abstract}

Keywords: optimism, hope, coping and academic motivation.

\section{INTRODUCTION}

In today's world education is indispensable for human progress and empowerment. Educators and psychologists play a major role to impart knowledge and enhance skills among first generation learners. The current education system raises expectations from students and the concern to perform better from peers is ever increasing. This has led to an interested aspect in educational psychology. Psychologists perceive motivation is one of the important key concepts to explain different levels of performance among students. It has been observed that factors such as such as optimism, hope, proactive coping and academic motivation are related to academic success among students. Previous research in this area of concentration has revealed that students who are hopeful and optimistic do better than counterparts.

\section{MOTIVATION}

The present paper puts forth academic motivation among students in light. Motivation is the process where goal directed activity is persuaded and maintained. It is the force that energizes and directs behaviour towards the goal (Eymur \& Gehan, 2011). In the current result driven educational system, it is one of the most important concepts in education psychology (Eggen \& Kanchak, 1994). There are three main types of motivation which are discussed as under (Deci \& Ryan, 1985).

*\&**, HSS Dept. Jaypee Institute of Information Technology, India,

(C) 2014 R. Gautam, S. Passi; licensee IJIP. This is an Open Access Research distributed under the terms of the Creative Commons Attribution License (http://creativecommons.org/licenses/by/2.0), which permits unrestricted use, distribution, and reproduction in any Medium, provided the original work is properly cited. 


\section{Assessing the Role of Coping Styles as Mediators for Hope and Optimism in Measuring Academic Motivation among First Generation Learners}

Intrinsic motivation arises from a desire to learn due to desire of self fulfillment, enjoyment and achieve success in particular area. Intrinsic motivation is an internal behavioral aspect that forms an inherent part of a person's character. Intrinsic motivation in an individual depicts inherent satisfaction (Ryan \& Deci, 2000; Vallerand \& Ratelle, 2002).

Extrinsic Motivation refers to a result oriented and task driven motivation in order to be successful. Their behaviour is enhanced by external elements including rewards and punishments. Research show that extrinsic motivation is about achieving success in order to ward off any punishments. Educational psychologists believe that grade-oriented students are extrinsically motivated, whereas students who are genuinely interested in gaining knowledge are instrincally motivated.

A motivation is depiction of belief that one's behaviour is the result of something out of conscious (Cokley 2000). It is the absence of any self determination (Deci\& Ryan, 1985). An example of an amotive student cannot explain the reason why he goes to college.

Evidences suggest that students who are highlymotivated are more likely to have increased level of academic achievement and have lower dropout rates (Blank, 1997). Other studies revealed positive relationships between motivation and academic performance and success (Gottfield, 1990; Grolnick, Ryan \& Deci 1991; Wong \& Csikszentmihalyi, 1991; Ames, 1992; Mtchell, 1992; Schiefele, Krapp \& Winteler, 1992; Fortier, Vallerand, Guay, 1995; Pintrich \& Maehr, 1995; Johnson, 1996; Green, Nelson, Martin, Marsh, 2001; McInerney,2001; Sandra, 2002; Eymur \& Geban, 2011).

The autonomy theory based on academic motivation by Deci and Schwartz describes the relationship between academic motivation and performance; based on grades received by the students and differentiated by gender. Research showed that gender is not a significant predictor for academic motivation (Jegede, 1994). Empirical evidence found that the average level of academic motivation decreased with increasing age (Hefer\& Stuart, 1998). Previousresearch on academic motivation among students has focused on gender, age, and psychological impact on individuals. Emphirical evidence on hope and optimism playing a role in academic motivation among students leading to better academic performance has been scanty.

\section{HOPE}

Psychologists laid emphasis on identifying psychological strengths that foster healthy development of human beings. One major tenet of positive psychology requires expertise and expanded view in assessment of traits and strengths, to stressful live events and life style factors (Master \& Coastsworth, 1998; Rutter 1994). Hope has received maximum attention with children and adolescents (Synder, Lopez \& Shorey, 2003). Numerous studies have depicted the importance of motivational factors in adolescent's academic and behavioral development 


\section{Assessing the Role of Coping Styles as Mediators for Hope and Optimism in Measuring Academic Motivation among First Generation Learners}

(Anderson \&Maehr 1994; Stipek 2002). Research on academic motivation have constantly depicted that students who believed that good grades are caused by internal and external causes (Weiner, 2000) and accepted their need and behavioral response (Bandura, 1997) attained higher levels of academic success. Research has also confirmed that school age students who have highly hopeful have better social interactions, self-esteem, optimism and academic achievement (Synder, Heavens et al. (1997), Snyder, Hoza et al. (1997).

Hope appears to be the key motivational construct in development of a positive psychology among students. The goal setting theory of hope depicts that hope exists when an individual has motivation to remain engaged with a future outcome and assume a way to reach a particular outcome. Therefore, goal setting theory focuses on hope as a cognitive set rather than emotion. The emotions that are associated with hope are seen as resulting from a goal-directed thought, with positive emotions reflecting perceived success in the pursuit of goals and negative emotions reflecting perceived failures (Synder et al; 1991, 2000).

Averill et al. (1990) established four rules of hope based on future appraisals. Firstly, hope is achieved when one evaluates the probability of acquisition of being realistic. Secondly, individuals hope only for what they appraise is personally or socially acceptable. Thirdly, only outcomes and events that are appraised as important are hoped for (priority rule). Fourthly, people who hope should willingly take appropriate action to achieve their goals if actions are possible.

Averill et al. (1990) revealed that majority of participants in his study described hoping for success in achievement related contexts and interpersonal relationships; also for wellbeing of others. Roseman, Spindel and Jose (1990) investigated hope as part of comprehensive appraisal theory of emotion and found that hope was more of positive emotion as situation was congruent with ones emotion. Moreover, participants rated their likelihood of hope outcomes as lower than those elicited joy, affection and pride.

\section{OPTIMISM}

Optimism is defined as a generalized expectancy that good as opposed to bad outcomes will generally occur when confronted with problems in life situations or circumstances. In general optimism denotes a positive attitude being part of positive psychology. It has been seen that some people are optimistic by nature and are more positive about life but it can also be adapted with right type of experiences. According to Seligman (1991), optimism can be enriched by selecting achievable goals. Optimism plays a role of positive mood, perseverance, good problem solver, academic and workplace success (Scheier et al 1992). Individuals are continuously engaged in efforts to overcome obstacles to their goals as long as further relates to success (Scheier et al 1992). Research shows thatcollege students who are more optimistic are better academic performers (Medlin U\& Green 2009). There has been a contrary view as well on this, 


\section{Assessing the Role of Coping Styles as Mediators for Hope and Optimism in Measuring Academic Motivation among First Generation Learners}

where Rand found no significant relationship between optimism and grade expectancy. The trait of optimism leads to cognitive, coping, contextual resources enhancing mental health. Optimism helps us face the difficulties and reach the target and achieve the goals. Optimistic people are consistent and courageous towards goals in life (Scheier\&Carver 1992) and are more suited to cope with stress. The trait of optimism leads to cognitive, coping, contextual resources enhancing academic motivation of students.

Student's coping strategies play a dominant role in the academic motivation; leaving a strong impact on approaches help them in planning and staying motivated in academic career.

When preparing for academic success, students using a problem focused coping strategies adopt strategic approaches to motivate them in their academic life, resulting in more positive affects. Moreover, avoidance coping tends to adopt a surface approach to studying (Appelhans \& Schmeck, 2002; Moneta, et al; 2007). Further outcome, determined student coping styles to enhance academic motivation is a major stake for research in educational psychology.

\section{COPING}

Researches in this area have generally discussed dimensions of coping mostly in pairs. For example, primary versus secondary control (Rothbaum, Weisz, \&Synder, 1982), mastery versus meaning (Taylor,1983), problem focused versus emotion focused coping (Lazarus, 1991), and assimilated versus accommodative coping (Brandstadler,1992). The primary-secondary control and mastery meaning strategies are earthy in nature. For example, when students first try to alter the demands that are at stake and plight find subjective meaning to it.(Schwarzer\&Taubert, 2002).

Lazarus (1991) defined two types of coping as problem focused and emotion focused coping. Problem focused coping helps to pacify stressful events, though considering emotion focused coping efforts to govern the emotional consequences of stressful events. Emotional focused coping including emotional social support is positively associated with growth (Marker \& Langer 2001). Moreover, coping has been considered as a follow up behavioral dimension after the occurrence of stressful events. Recently psychologist have started emphasize more on proactive coping (Greenglass,Schwarzer,Jakubiec, Fiksenbaum,Taubert,1999).

\section{PROACTIVE COPING}

Previous researchers viewed coping as an adaptive reaction to stressful experiences, termed as reactive, a technique to be used once stress has been felt. It is a process developed in the context of a situation appraised as personally significant and exceeding one's resources for coping (Lazarus \&Folkman 1984). It is initiated if an individual's goal is threatened or lost. Moreover, psychologist assessed coping mainly in terms of their effectiveness in regulating distress. In the present scenario, coping mainly is seen as having multiple positive functions, to cope before stress sets in. 


\section{Assessing the Role of Coping Styles as Mediators for Hope and Optimism in Measuring Academic Motivation among First Generation Learners}

A new development in coping research focuses on proactive coping. Proactive coping relates that some individuals tend to live their lives in a way that they could collect assets and fight for unexpected obstacles. Proactive coping is still to be explored and studied in its details; we need to explore coping styles such as venting and suppression (Carver, Scheier\&Weintrauves, 1989). Proactive coping is a forward looking strategy, integrating processes of person quality of life management of those of self regulatory goal attainment (Greenglass, Schwarzer\&Taubert, 1999). Proactive coping is more future oriented and helps in goal management. The motivation for proactive is more positive, it results in perceiving situations as challenging, positive contributions to individual's behaviour and cognitive coping (Greenglass, 1993).

The proactive coping perspective may best be described by Zea\& Tyler (1996) as a general step or orientation that pervades the way an individual approaches life activities, facilating positive outcomes $(\mathrm{p}, 331)$. To help individuals reduce or modify stressful events in life, proactive coping can improve one's quality of life. The skills which enhance this behaviour include planning, goal setting, organization and mental stimulation (Aspinwall\& Taylor).

\section{EMOTIONAL SUPPORT SEEKING}

Emotional support refers to students general perception in a particular situation or circumstance, when a student works on a difficult assignment or worry about lack of social connectedness in his life. Review of literature in this regard reveal that emotional support as a construct has been measured as student's general perception of the teacher as warm and friendly (De Wit, Karoja, Ryef Shain2011; Wentzel et al; 2010).

Student's perception of emotional support is related to their feelings of relatedness or connectedness (Marchand \& Skinner, 2007). Furthermore, these validate how they feel when they are with their mentors. Previous research has revealed that positive perception of teachers as emotionally supportive is associated with positive educational outcomes among students. It was noted that students who feel emotionally supported are more likely to work harder towards their goals (Goodenow \& Grady 1993;Wentzel, 1994); ask for support and use self regulated learning strategies (Newman \& Schwager, 1993; Ryan \& Patinet 2001). An interesting question was whether the relations between hope and optimism effect measures of academic motivation; at least partially mediated by emotional support seeking.

\section{AVOIDANCE COPING}

Avoidance coping is defined as an attempt to escape from a problem and deal indirectly with it (Roth \& Cohen, 1986). Previous research depicted avoidance coping is linked to variety of demographic (e.g; age; Folkman et al; 1987), interpersonal (e.g; lack of social support; Manne et al; 2005), and problem specific (e.g uncontrollable stressors; Rayburn et al; 2005) factors. 


\section{Assessing the Role of Coping Styles as Mediators for Hope and Optimism in Measuring Academic Motivation among First Generation Learners}

\section{COPING \& OPTIMISM}

Research has suggested the importance of optimism as an important regulator in how people cope with stressful events. Optimists are considered proactive coper who evaluate difficulties in positive way, views tough times as challenges instead of threats. Hence, proactive coping tendencies predict psychological wellbeing over and above the effects of being optimistic.People who are resistant to coping work harder in stressful circumstances. Previous research in this area of concentration further revealed that optimism was positively associated with two subsets of engagement coping responses:1) problem focused and 2) emotional focused.Optimists were responsible for stressor confronted; they further controlled stressors with problem focused coping approach. Optimists are flexible to change and adapt to new situations and circumstances.

\section{HOPE \& OPTIMISM}

Both concepts have been thoroughly reviewed in last decades within the framework of positive psychology which give emphasis on human growth and strengths as well. It was noted that hope and optimism have been well used in daily practises; research has proven that they are correlated but manifest construct (Gallagher \&Lopez,2009; Ho et al; 2011; Magaletta\& Oliver, 1999; Wong $\&$ Lim, 2009). Hope was visualized as a route to motivate oneself and reach a determined goal (Synder, 2002).

\section{ABOUT THE PAPER}

The present paper aims to understand the relationship between hope and optimism as a predictor of academic motivation among students. It aims to understand that if a student is hopeful and optimistic, then what is the underlying association of these constructs with the academic motivation among students that helps them perform better in their academic life.

The present paper also aims at understanding the role of coping (avoidance, proactive and emotional coping) as a mediator between hope and optimism and academic motivation. The present paper discusses two models of mediation as shown below.

Model 1

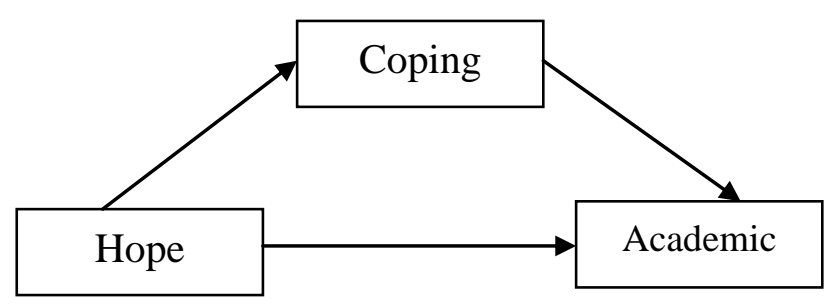

Model 2

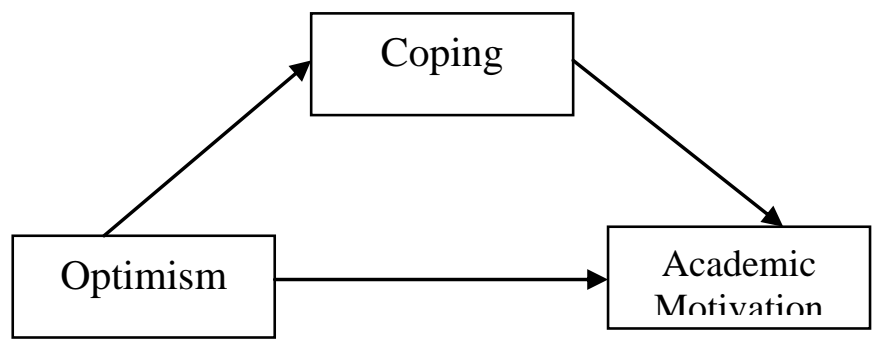




\section{Assessing the Role of Coping Styles as Mediators for Hope and Optimism in Measuring Academic Motivation among First Generation Learners}

\section{THE MEDIATING ROLE OF COPING STYLES}

We are proposing that proactive coping, avoidance coping and emotion coping mediate the relationship between hope and optimism affect academic motivation. Baron and Kenny (1986)posit that mediation is supported if each of the following is demonstrated: (a)The first regression equation shows that the independent variable relates to the dependent variable, (b) the second equation shows that the independent variable relates to the mediating variable, and (c) the third regression shows that the mediating variable relates to the dependent variable and the relationship of the independent variable with the dependent variable is significantly lower in magnitude in the third equation than in the second. Support for full mediation can be argued when the independent variable does not relate to the dependent variable when the mediating variable is added to the equation.

\section{PARTICIPANTS}

One hundred and twenty college students ( 83 males and 37 females) were randomly selected. All these students were in the engineering class and had a subject of psychology in their syllabus.A descriptive analysis of the sample that was covered for the present research paper is mentioned as under.

\begin{tabular}{llll}
\hline Gender & Mean Age & Range & SD \\
\hline Male & 18.81 & 6 & 1.294 \\
Female & 19 & 6 & 1.536 \\
\hline
\end{tabular}

\section{RESEARCH INSTRUMENTS}

The present research paper is based on a series of standardized scales for the different behavioral constructs that have been analyzed. A detail of the same in regard to the scales that have used in the present paper is described as under.

Optimism Scale: The life orientation test by Scheier (1994) was used to measure the levels of optimism level of an individual. The scale is a 10-item Likert scale with options ranging from strongly disagree (0) to strongly agree (4). The scale has cronbach alpha of 0.95 .

The Adult Hope Scale: The scale was developed by Synder (1991). It consists of 12 items measuring dispositional hope. It consists of 12-items developed on 8-point Likert-type scale ranging from 1 (definitely false) to 8 (definitely true). The scale has cronbach alpha of 0.78 .

Proactive Coping Scale: The scale was developed by Esther Greenglass consists of 14 items and combines autonomous goal setting with self-regulatory goal attainment cognitions and behaviour. The proactive coping subscale consists of 14 items and ratings are made on a5-point 


\section{Assessing the Role of Coping Styles as Mediators for Hope and Optimism in Measuring Academic Motivation among First Generation Learners}

scale from 1 (not at all true) to 4 (completely true). The final internal consistency in the current sample was acceptable for the proactive coping subscale $(\alpha=.66)$.

Academic Motivation Scale: This scale was used to assess students' academic motivation. This scale is composed of seven subscales with four items. Three subscales assess types of intrinsic motivation: motivation to know, to accomplish things, and to experience stimulation.

The three intrinsic subscales were combined to form one intrinsic motivation subscale

(Vallerand \& Ratelle, 2002). The other three subscales assess three types of extrinsic motivation: external regulation, interjected regulation, and identified regulation, the latter assessing a motivation. Students were asked, "Why are you pursuing academic activities?" The 28 items were scored on a 7-point scale (i.e.,from 1 "Do not agree at all" to 7 "Very strongly agree"). Alpha coefficients obtained for those seven subscales ranged from .62 to .87.

\section{PROCEDURE}

The survey forms containing all four scales (Optimism Scale, The Adult Hope Scale, Proactive Coping Scale and Academic Motivation Scale) and demographic questions were administered to the randomly selected group of students. Before asking the students to provide their responses, they were provided information about the purpose of the study and an informed consent was taken. The respondents were allowed and encouraged to express their honest feelings without any bias.

\section{RESULTS AND INTERPRETATIONS}

The models of mediation were tested for all the three kinds of coping styles (avoidance coping, proactive coping and emotional coping) with the independent variables hope and optimism separately to see their impacts on the dependant variable (academic motivation). The results below deal each of the models separately.

\section{Model 1:}

The specifications of the model are mentioned as under: Independent Variable (IV) : Optimism Mediating Variable (MV) : Avoidance Coping Dependant Variable (DV) : Academic motivation

The current model assumes that optimism is a predictor for academic motivation and it exerts its influence through a mediating variable called avoidance coping. This means that the effect of being optimistic and having a good academic performance is routed through how well students handle his/her difficult situations of failure and remain focused and optimistic.

Further the relationships have been tested using linear regression and three such regression equations were built and tested, as shown in the grid below. 


\begin{tabular}{|lll|}
\hline Regression Equation & DV & IV(s) \\
\hline Equation 1 & $\begin{array}{l}\text { Academic } \\
\text { Motivation }\end{array}$ & Optimism \\
\hline Equation 2 & $\begin{array}{l}\text { Avoidance } \\
\text { Coping }\end{array}$ & Optimism \\
\hline Equation 3 & $\begin{array}{l}\text { Academic } \\
\text { Motivation }\end{array}$ & $\begin{array}{l}\text { Optimism Avoidance Coping } \\
\text { And }\end{array}$ \\
\hline
\end{tabular}

Results from the three regression equations are summarized in the table as under.

\begin{tabular}{|c|c|c|c|c|c|c|c|c|c|c|}
\hline Variables & & $\beta$ & $\begin{array}{l}\text { Std. } \\
\text { Error }\end{array}$ & $\mathrm{T}$ & Sig. & $\mathrm{R}$ & $\mathrm{R}^{2}$ & $\begin{array}{l}\text { Adjust } \\
\text { ed R }\end{array}$ & $\mathrm{F}$ & Sig. \\
\hline Equation 1 & & 0.205 & 0.114 & $\begin{array}{l}-1.799 \\
\end{array}$ & 0.075 & $.163^{\mathrm{a}}$ & 0.027 & 0.018 & 3.238 & $.075^{\mathrm{b}}$ \\
\hline Equation 2 & & -.027 & .024 & -1.094 & .276 & $.100^{\mathrm{a}}$ & .010 & .002 & 1.197 & $.276^{\mathrm{b}}$ \\
\hline \multirow{2}{*}{$\begin{array}{l}\text { Equation } \\
3\end{array}$} & $\begin{array}{l}\text { Avoidanc } \\
\text { e Coping }\end{array}$ & -0.731 & 0.458 & -1.594 & 0.114 & $.218^{\mathrm{a}}$ & 0.047 & 0.031 & 2.911 & $.058^{\mathrm{b}}$ \\
\hline & Optimism & 0.191 & 0.113 & -1.686 & 0.094 & & & & & \\
\hline
\end{tabular}

Results from equation 1 shows that Optimism is a significant predictor of Academic Motivation at $90 \%$ Confidence Interval $(\mathrm{p}<0.1)$. The model explains only around $3 \%$ of the variation in the dependant variable $\left(\mathrm{R}^{2}=0.027\right)$.

Further exploring for mediation effects, equation 2 explores if Optimism is a predictor for Avoidance Coping. Results show that there is no significant relationship between the two at 95\% Confidence Interval $(\mathrm{p}=0.276)$. This leads to the fact that there is no mediation effect that needs to be tested in a further model as there is no significant relationship between the predictor and moderator in the mediation model.

Still, we further tested the same to have a confirmatory approach in Model 3 with Academic Motivation as the Dependant variable and Optimism and Avoidance Coping as the predictors. Results show that Avoidance Coping is not a significant predictor of Academic Motivation at 90\% CI ( $\mathrm{p}=0.114)$.

Results show that optimistic state of mind does lead to a better academic performance, sans the effect of avoidance coping. Further digging might also lead to the fact that avoidance coping is a temporary state of mind and a more grounding behavioural aspect like being optimistic rules over the fact.

\section{Model 2:}

The specifications of the model are mentioned as under: Independent Variable (IV) : Optimism Mediating Variable (MV) : Emotional Coping Dependant Variable (DV) : Academic motivation 


\section{Assessing the Role of Coping Styles as Mediators for Hope and Optimism in Measuring Academic Motivation among First Generation Learners}

The current model assumes that optimism is a predictor for academic motivation and it exerts its influence through a mediating variable called emotional coping. The model assumes that being optimistic does help in higher academic motivation, but is also governed by how well a student handles his/her emotions.

Further the relationships have been tested using linear regression and three such regression equations were built and tested, as mentioned in the grid below.0

\begin{tabular}{|lll|}
\hline Regression Equation & DV & IV(s) \\
\hline Equation 1 & $\begin{array}{l}\text { Academic } \\
\text { Motivation }\end{array}$ & Optimism \\
\hline Equation 2 & $\begin{array}{l}\text { Emotional } \\
\text { Coping }\end{array}$ & Optimism \\
\hline Equation 3 & $\begin{array}{l}\text { Academic } \\
\text { Motivation }\end{array}$ & $\begin{array}{l}\text { Optimism Emotional Coping and } \\
\text { E }\end{array}$ \\
\hline
\end{tabular}

Results from the three regression equations are summarized in the table as under.

\begin{tabular}{lllllllllll}
\hline Variables & & $\beta$ & $\begin{array}{l}\text { Std. } \\
\text { Error }\end{array}$ & T & Sig. & R & $\mathrm{R}^{2}$ & $\begin{array}{l}\text { Adjust } \\
\text { ed R }\end{array}$ & F & Sig. \\
\hline Equation 1 & & 0.205 & 0.114 & -1.799 & 0.075 & $.163^{\mathrm{a}}$ & 0.027 & 0.018 & 3.238 & $.075^{\mathrm{b}}$ \\
Equation 2 & & .085 & .039 & 2.148 & .034 & $.194^{\mathrm{a}}$ & .038 & .029 & 4.615 & $.034^{\mathrm{b}}$ \\
\multirow{2}{*}{$\begin{array}{lllll}\text { Equation } \\
3\end{array}$} & $\begin{array}{l}\text { Emotional } \\
\text { Coping }\end{array}$ & 0.073 & 0.268 & 0.272 & 0.786 & $.165^{\mathrm{a}}$ & 0.027 & 0.011 & 1.643 & $.198^{\mathrm{b}}$ \\
& Optimism & 0.211 & 0.117 & -1.811 & 0.073 & & & & & \\
\hline
\end{tabular}

Result from equation 2 for mediation effects shows that there is a significant relationship between academic motivation and emotional coping at 95\% Confidence Interval ( $\mathrm{p}=0.034)$. This leads to the fact that there might be a mediation effect that needs to be tested in a further equation.

We further tested the same to have a confirmatory approach in equation 3 with Academic Motivation as the Dependant variable and Optimism and Emotion Coping as the predictors. Results show that emotion Coping is not a significant predictor of Academic Motivation at $90 \%$ CI $(\mathrm{p}=0.786)$.

Partial Mediation

Since equation 2 was significant at 0.034 it is partial mediation between Emotion coping and academic motivation.

\section{Model 3:}

The specifications of the model are mentioned as under:

Independent Variable (IV) : Optimism

Mediating Variable (MV) : Proactive Coping

Dependant Variable (DV) : Academic motivation 


\section{Assessing the Role of Coping Styles as Mediators for Hope and Optimism in Measuring Academic Motivation among First Generation Learners}

The current model assumes that optimism is a predictor for academic motivation and it exerts its influence through a mediating variable called proactive coping. This means that the effect of being optimistic and having a good academic performance is routed through how well students handle his/her difficult situations of failure and remain focused and optimistic.

Further the relationships have been tested using linear regressions and three such regression equations were built and tested, as mentioned in the grid below.

\begin{tabular}{|llll|} 
Regression Equation & DV & IV(s) \\
\hline Equation 1 & $\begin{array}{l}\text { Academic } \\
\text { Motivation }\end{array}$ & Optimism & \\
\hline Equation 2 & Proactive Coping & Optimism & \\
\hline Equation 3 & Academic & Optimism & and \\
& Motivation & Proactive Coping & \\
\hline
\end{tabular}

Results from the three regression equations are summarized in the table as under.

\begin{tabular}{|c|c|c|c|c|c|c|c|c|c|c|}
\hline Variables & & $\beta$ & $\begin{array}{l}\text { Std. } \\
\text { Error }\end{array}$ & $\mathrm{T}$ & Sig. & $\mathrm{R}$ & $\mathrm{R}^{2}$ & $\begin{array}{l}\text { Adjust } \\
\text { ed } R^{2}\end{array}$ & $\mathrm{~F}$ & Sig. \\
\hline Equation 1 & & 0.205 & 0.114 & $\begin{array}{l}-1.799 \\
\end{array}$ & 0.075 & $.163^{\mathrm{a}}$ & 0.027 & 0.018 & 3.238 & $.075^{\mathrm{b}}$ \\
\hline Equation 2 & & .036 & .063 & .579 & .564 & $.053^{\mathrm{a}}$ & .003 & -.006 & .336 & $.564^{\mathrm{b}}$ \\
\hline \multirow{2}{*}{$\begin{array}{l}\text { Equation } \\
3\end{array}$} & $\begin{array}{l}\text { Proactive } \\
\text { Coping }\end{array}$ & 0.563 & 0.159 & 3.53 & 0.001 & \multirow[t]{2}{*}{$.347^{\mathrm{a}}$} & \multirow[t]{2}{*}{0.12} & \multirow[t]{2}{*}{0.105} & \multirow[t]{2}{*}{8.008} & \multirow[t]{2}{*}{$.001^{\mathrm{b}}$} \\
\hline & Optimism & 0.225 & 0.109 & -2.07 & 0.041 & & & & & \\
\hline
\end{tabular}

Exploring for mediation effect of proactive coping, equation 2 explores if Optimism is a predictor for Proactive Coping. Results show that there is no significant relationship between the two at $95 \%$ Confidence Interval $(\mathrm{p}=0.564)$. This leads to the fact that there is no mediation effect that needs to be tested in a further model as there is no significant relationship between the predictor and moderator in the mediation model.

Still, we further tested the same to have a confirmatory approach in Model 3 with Academic Motivation as the Dependant variable and Optimism and Proactive Coping as the predictors. Results show that proactive Coping is highly significant predictor of Academic Motivation at 99\% CI ( $\mathrm{p}=0.001)$.

\section{Model 4:}

The specifications of the model are mentioned as under: Independent Variable (IV) : Hope Mediating Variable (MV) : Avoidance Coping Dependant Variable (DV) : Academic motivation 


\section{Assessing the Role of Coping Styles as Mediators for Hope and Optimism in Measuring Academic Motivation among First Generation Learners}

The current model assumes that hope is a predictor for academic motivation and it exerts its influence through a mediating variable called avoidance coping. This means that the effect of being hopeful and having a good academic performance is routed through how well person/students handle his/her difficult situations of failure and remain focussed and hopeful.

Further the relationships have been tested using linear regressions and three such regression equations were built and tested, as mentioned in the grid below.

\begin{tabular}{|lll|}
\hline Regression Equation & DV & IV(s) \\
\hline Equation 1 & Academic & Hope \\
& Motivation & \\
\hline Equation 2 & Avoidance Coping & Hope \\
\hline Equation 3 & Academic & Hope and Avoidance \\
& Motivation & Coping \\
\hline
\end{tabular}

Results from the three regression equations are summarized in the table as under.

\begin{tabular}{lllllllllll}
\hline Variables & & $\beta$ & $\begin{array}{l}\text { Std. } \\
\text { Error }\end{array}$ & T & Sig. & R & $\mathrm{R}^{2}$ & $\begin{array}{l}\text { Adjust } \\
\text { ed R }\end{array}$ & F & Sig. \\
\hline Equation 1 & & 0.246 & 0.122 & 2.014 & 0.046 & $.182^{\mathrm{a}}$ & 0.033 & 0.025 & 4.056 & $.046^{\mathrm{b}}$ \\
Equation 2 & & -.027 & .024 & -1.094 & .276 & $.100^{\mathrm{a}}$ & .010 & .002 & 1.197 & $.276^{\mathrm{b}}$ \\
\multirow{2}{*}{$\begin{array}{ll}\text { Equation } \\
3\end{array}$} & $\begin{array}{l}\text { Avoidanc } \\
\text { e Coping }\end{array}$ & 0.227 & 0.122 & 1.861 & 0.065 & $.229^{\mathrm{a}}$ & 0.052 & 0.036 & 3.23 & $.043^{\mathrm{b}}$ \\
& Hope & -0.704 & 0.458 & -1.535 & 0.127 & & & & & \\
\hline
\end{tabular}

Results from equation 1 shows that Hope is a significant predictor of Academic Motivation at 95\% Confidence Interval ( $\mathrm{p}<0.05$ ). The equation explains only around $3 \%$ of the variation in the dependant variable $\left(\mathrm{R}^{2}=0.033\right)$.

Further exploring for mediation effects, equation 2 explores if Hope is a predictor for Avoidance Coping. Results show that there is no significant relationship between the two at $99 \%$ Confidence Interval ( $p=0.276$ ). This leads to the fact that there is no mediation effect that needs to be tested in a further model as there is no significant relationship between the predictor and moderator in the mediation model.

Still, we further tested the same to have a confirmatory approach in Model 3 with Academic Motivation as the Dependant variable and Hope and Avoidance Coping as the predictors. Results show that Avoidance Coping is not a significant predictor of Academic Motivation at 90\% CI $(\mathrm{p}=0.065)$. 


\section{Model 5:}

The specifications of the model are mentioned as under:

Independent Variable (IV) : Hope

Mediating Variable (MV) : Emotional Coping

Dependant Variable (DV) : Academic motivation

The current model assumes that hope is a predictor for academic motivation and it exerts its influence through a mediating variable called emotional coping. This means that the effect of being hopeful and having a good academic performance is routed through how well person/students handle his/her difficult situations of failure and remain focused and hopeful.

Further the relationships have been tested using linear regressions and three such regression equations were built and tested, as mentioned in the grid below.

\begin{tabular}{|lll|}
\hline Regression Equation & DV & IV(s) \\
\hline Equation 1 & $\begin{array}{l}\text { Academic } \\
\text { Motivation }\end{array}$ & Hope \\
\hline Equation 2 & Emotional Coping & Hope \\
\hline Equation 3 & $\begin{array}{l}\text { Academic } \\
\text { Motivation }\end{array}$ & $\begin{array}{l}\text { Hope and Emotional } \\
\text { Coping }\end{array}$ \\
\hline
\end{tabular}

Results from the three regression equations are summarized in the table as under.

\begin{tabular}{|c|c|c|c|c|c|c|c|c|c|c|}
\hline Variables & & $\beta$ & $\begin{array}{l}\text { Std. } \\
\text { Error }\end{array}$ & $\mathrm{T}$ & Sig. & $\mathrm{R}$ & $\mathrm{R}^{2}$ & $\begin{array}{l}\text { Adjust } \\
\text { ed } R^{2}\end{array}$ & $\mathrm{~F}$ & Sig. \\
\hline Equation 1 & & 0.246 & 0.122 & 2.014 & 0.046 & $.182^{\mathrm{a}}$ & 0.033 & 0.025 & 4.056 & $.046^{\mathrm{b}}$ \\
\hline Equation 2 & & .092 & .042 & 2.174 & .032 & $.196^{\mathrm{a}}$ & .039 & .030 & 4.726 & $.032^{\mathrm{b}}$ \\
\hline \multirow{2}{*}{$\begin{array}{l}\text { Equation } \\
3\end{array}$} & $\begin{array}{l}\text { Emotional } \\
\text { Coping }\end{array}$ & -0.129 & 0.267 & -0.484 & -0.629 & \multirow[t]{2}{*}{$.188^{\mathrm{a}}$} & \multirow[t]{2}{*}{0.035} & \multirow[t]{2}{*}{0.019} & \multirow[t]{2}{*}{2.132} & \multirow[t]{2}{*}{$.123^{\mathrm{b}}$} \\
\hline & Hope & 0.258 & 0.125 & 2.063 & 0.041 & & & & & \\
\hline
\end{tabular}

Results from equation 1 shows that Hope is a significant predictor of Academic Motivation at 95\% Confidence Interval $(\mathrm{p}<0.05)$.Further exploring for mediation effects, equation 2 explores if Hope is a predictor for Emotional Coping. Results show that there is significant relationship between the two at 95\% Confidence Interval ( $\mathrm{p}=0.032$ ). This leads to the fact that there might be a mediation effect that needs to be tested in a further model as there is significant relationship between the predictor and moderator in the mediation model.

Further testing for a confirmatory approach in equation 3 with Academic Motivation as the Dependant variable and Hope and emotional Coping as the predictors. Results show that Emotional Coping is not a significant predictor of Academic Motivation at 90\% CI $(p=-0.629)$. 


\section{Assessing the Role of Coping Styles as Mediators for Hope and Optimism in Measuring Academic Motivation among First Generation Learners}

Results show that the mediation effect is not channeled through emotional coping, but the latter has an extraneous impact on the outcome variable of academic motivation.

Model 6:
The specifications of the model are mentioned as under:
Independent Variable (IV) : Hope
Mediating Variable (MV) $\quad$ : Proactive Coping
Dependant Variable (DV) : Academic motivation

The current model assumes that hope is a predictor for academic motivation and it exerts its influence through a mediating variable called proactive coping. This means that the effect of being hopeful and having a good academic performance is routed through how well person/students handle his/her difficult situations of failure and remain focused and hopeful.

Further the relationships have been tested using linear regressions and three such regression equations were built and tested, as mentioned in the grid below.

\begin{tabular}{|lll|}
\hline Regression Equation & DV & IV(s) \\
\hline Equation 1 & $\begin{array}{l}\text { Academic } \\
\text { Motivation }\end{array}$ & Hope \\
\hline Equation 2 & Proactive Coping & Hope \\
\hline Equation 3 & $\begin{array}{l}\text { Academic } \\
\text { Motivation }\end{array}$ & $\begin{array}{l}\text { Hope and Proactive } \\
\text { Coping }\end{array}$ \\
\hline
\end{tabular}

Results from the three regression equations are summarized in the table as under.

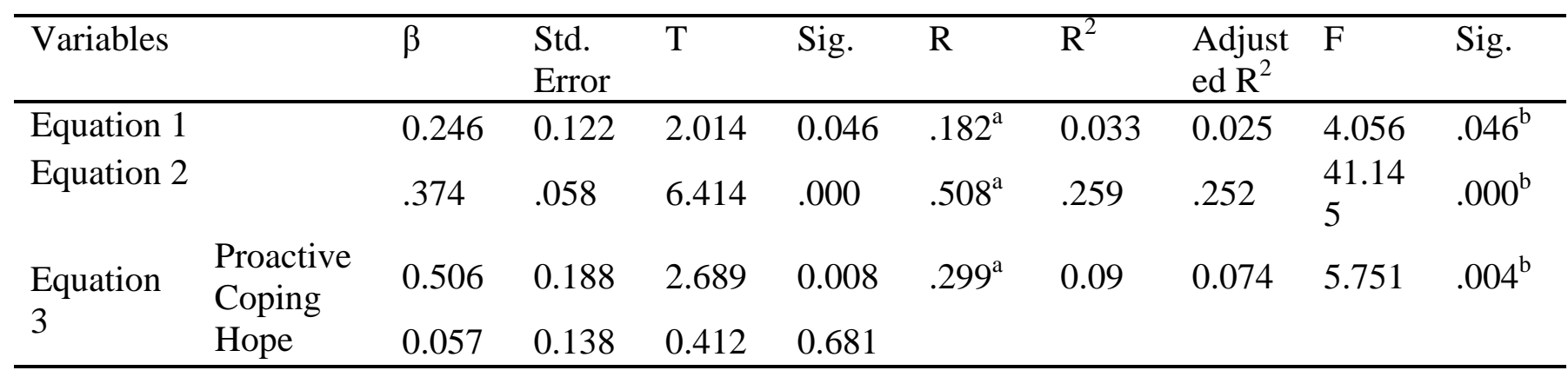

Results from equation 1 shows that Hope is a significant predictor of Academic Motivation at 95\% Confidence Interval ( $\mathrm{p}<0.05)$.

Further exploring for mediation effects, equation 2 explores if Hope is a predictor for proactive Coping. Results show that there is significant relationship between the two at $99 \%$ Confidence Interval $(\mathrm{p}=0.000)$. This leads to the fact that there might be a mediation effect of proactive coping on academic motivation that needs to be tested in a further confirmatory model. 


\section{Assessing the Role of Coping Styles as Mediators for Hope and Optimism in Measuring Academic Motivation among First Generation Learners}

Equation 3 tests the mediation effect with Academic Motivation as the Dependant variable and Hope and proactive Coping as the predictors. Results show that proactive Coping is a significant predictor of Academic Motivation at $99 \%$ CI ( $\mathrm{p}=0.008)$.

\section{Partial Mediation}

Since from equation 1 to equation 3 , the standardized regression coefficient of hope is reduced by 0.189 points, that confirms that there is a partial mediation effect of proactive coping on hope in determining academic motivation among students.

\section{DISCUSSION}

Academic motivation was analyzed with optimism as predictor variable it was seen at a $\mathrm{p}$ value of.075 with $\mathrm{F}$ statistic of 3.328. The model explains $1.8 \%$ of variance in the dependent variable academic motivation (Adjusted R Square $=.018$ ). We have used linear regression model where independent variable hope and optimism, dependent variable academic motivation and moderating variable is avoidance coping, proactive coping and emotion coping. Optimism as an independent variable doesn't have an impact on academic motivation score of students $(\mathrm{p}=.075$ at $95 \%$ confidence interval). But the results of regression show that the interaction variables have a significant impact on academic score. Thus results depicted the performance indicator of academic motivation score doesn't only on cognitive dimension of optimism, but non cognitive dimension has a fair role to play in improving performance indicator. Hope as an individual variable is significant and all interaction variables are significant. Students hope that they will get better marks in future and put better effort. Whereas, optimistic individuals are not putting better effort, have to work towards it. So, this shall enhance impact on academic motivation.

There are no significant relationship between hope and avoidance coping and similarly no significant relationship with emotional coping in second model of linear regression analysis. The findings reported a significant relationship between hope and proactive coping which further depicts partial mediation. The increase in hope was expected and consistent relationships with other studies to foster goal-directed thinking (Cheavens et al.2006;Curry et al; 1999; Klausner et al 1998,2000; Lopez et al.2000a;MacLeod et al.2007). We suggest further research include hope measures to suspect this relationship. Nevertheless future studies are needed to further examine this issue. In the present study the result is statistically significant by time but unlikely to be a meaningful finding.

\section{FUTURE SCOPE}

Enhancing hope in teachers leads to hopeful youth. The keen observations noted facilitating adjustment in youth through direct intervention and consultation for youth problems and fears. Faculty fraternity must establish must establish an atmosphere where students must plants seeds of hope in their life and career goals. Students must be open to doors of growth building stretch wherein students can enhance from previous knowledge or insights. Academicians play essential 


\section{Assessing the Role of Coping Styles as Mediators for Hope and Optimism in Measuring Academic Motivation among First Generation Learners}

and vital role in keeping individuals engaged and help them flourish in their life goals also achieve targets outside college.

Hope can flow from one person to another's life, maximizes growth and positive living. Psychologist can facilitate hope and help students increase and achieve academic motivation. We observed maximizing hope thinking in academic settings, encourages growth of human, mind-set and performance. Everyone's hope can grow through their target and avoiding negative people and environment. Hopeful thinking can enhance and enlighten lifetime learning and psychologist helps them to keep this lesson alive.

\section{REFERENCES}

1. Aldwin, C. M. (1999). Stress, coping, and development: An integrative approach. New York:Guilford.

2. Aldwin, C. M., \&Revenson, T.A. (1987). Does coping help? A re-examination of the relationshipbetween coping and mental health. Journal of Personality and Social Psychology, 53, 337-348.

3. Barron, R. M., \& Kenny, D. A. (1986). The mediator-moderator variable distinction in social psychological research: Conceptual, strategic, and statistical considerations. Journal of Personality and Social Psychology, 51, 1173-1182

4. Bossert, S., Berger, M., Krieg, J. C., Schrieber, W., Junker, M., \& von Zerssen, S. (1988). Cortisolresponse to various stressful situations: Relationship to personality variables and coping styles.Neuropsychobiology, 20, 36-42.

5. Carver, C. S., Scheier, M. F., \& Weintraub, J. K. (1989). Assessing coping strategies: A theoretically-based approach. Journal of Personality and Social Psychology, 56, 267-283 Eriksen, H. R., \&Ursin, H. (1999).

6. D. B. (2003). Hope theory, measurements, and applications to school psychology. School Psychology Quarterly, 18, 122-139.

7. Snyder, C. R., \&Dinoff, B. L. (1999). Coping: Where have you been? In C. R. Snyder (Ed.),Coping: The psychology of what works (pp. 3-19). New York: Oxford University Snyder, C. R., Lopez, S. J., Shorey, H. L., Rand, K. L., \& Feldman,

8. Subjective health complaints: Is coping more important thancontrol? Work \& Stress, 13, 238-252.Folkman, S., \& Moskowitz, J. T. (2000).Positive affect and the other side of coping.American Psychologist, 55, 647-654.

9. Yi, J. P., Smith, R. E., Vitaliano, P. P. (2005). Stress- resilience, illness, and coping: A person-focused investigation of young women athletes. Journal of Behavioral Medicine, 